This is the version of the article/chapter accepted for publication in Theory and Struggle, 122 (1). pp. 46-57 published by Liverpool University Press.

https://doi.org/10.3828/ts.2021.6

Re-use is subject to the publisher's terms and conditions

Accepted version downloaded from SOAS Research Online: http://eprints.soas.ac.uk/35477

\title{
Food, Diet and the Pandemic ${ }^{1}$
}

\section{Introduction}

The impact of Covid-19 is linked to underlying health conditions, many of which are related to diet, such as obesity, heart disease and diabetes. The incidence and severity on those with diabetes is particularly harsh - accounting for one-third of all recorded hospitals deaths in the $\mathrm{UK}^{2}$

The virus reflects a longstanding link between diet and health outcomes. Malnutrition is the leading cause of ill health and death worldwide (Development Initiatives 2020). The emergence of the pandemic and the link to poor diet has highlighted the inequality in nutrition outcomes both within and across nations. Currently, one in nine people in the world is hungry, and one in three is overweight or obese. More and more countries experience the double burden of malnutrition, where undernutrition coexists with obesity leading to other diet-related non-communicable diseases (NCDs). Efforts encouraging individuals to eat healthier diets have been unsuccessful. The origins of health outcomes from poor diet are systemic, not due to poor choice or knowledge: "Unequal nutrition outcomes are rooted in deeper inequities that arise from unjust systems and processes that structure everyday living conditions" (Development Initiatives 2020, p 21).

But how should such issues be researched? This is explored in our new book $A$ guide to the systems of provision approach: Who gets what, how and why? The Systems of Provision (SoP) approach uses a range of academic influences, with Marxist Political Economy to the fore, setting out a framework for analysing the systems by which goods and services are provided, and their influences on consumption outcomes. The SoP approach was developed to support empirical research that acknowledges social, cultural and material aspects of specific provisioning systems, themselves embedded in an understanding of the dynamics of global capitalism (Mattioli et al 2020). This paper draws on the SoP approach to understand the drivers of poor health outcomes and consequential increased severity of Covid-19 on some social strata.

Section 2 provides an overview of the emerging epidemic in malnutrition and its costs. Section 3 considers the systems which contribute to these outcomes, the roles played by the underlying system of production and the corresponding systems and cultures of consumption. The paper concludes with recommendations for ways forward.

\section{The malnutrition epidemic}

According to the World Health Organisation worldwide obesity tripled between 1975 and 2016. In $201639 \%$ of adults were overweight and $13 \%$ of the world's adult population was obese (https://www.who.int/news-room/fact-sheets/detail/obesity-and-overweight). ${ }^{3}$ For the USA, nearly $71.6 \%$ of adults are overweight or obese (Mande et al 2020, p.13). The UK is not far behind, with one of the highest obesity rates in Europe (OECD 2017). The number of obese adults in England almost doubled between 1997 and 2017 (Diabetes UK 2019). In $2018,63 \%$ of adults were overweight or obese (NHS Digital 2020). A third of children leaving primary school are overweight or obese (NHS 2019).

Poor diet caused 11million deaths, 22\% of the global total, in 2017 (GBD 2017 Diet Collaborators, 2019). Obesity is a significant risk factor in a range of chronic diseases, 
particularly type 2 diabetes, cardiovascular disease and types of cancer. In the USA, 100 million people suffer from diabetes or pre-diabetes, while one in three children born after 2000 is expected to develop Type 2 diabetes (Mande et al 2020, p.13). In England, rising obesity is behind a sharp increase in cases of type 2 diabetes. The situation is deteriorating. Diabetes UK reports that 3.9 million people are currently living with a diagnosis of diabetes (and $90 \%$ of those with type 2), up from $1.9 \%$ in 1998 (https://www.diabetes.org.uk/about_us/news/diabetes-prevalence-statistics). In 2018/19 there were over 876,000 hospital admissions where obesity was a factor, an increase of 23 percent on the previous year and almost 700 children (under 16) were admitted to hospital because of obesity (NHS Digital 2020).

Worryingly, economic development would appear to bring obesity, with China's experience particularly telling with a tenth of its population now suffering diabetes, double the rate even of the UK, even though type 2 diabetes (the result primarily of being overweight, not least through consumption of sugar) was practically unknown in China two decades previously. For the first time in American history, life expectancies are falling, with declines for three consecutive years due in part to significant increases in mid-life mortality from diet-related diseases (Mande et al 2020). In the UK, the Institute of Actuaries reported that life expectancy in 2018 had declined by just over a year since 2015 (IFA 2019). The impact on mortality rates of Covid-19 are not yet known but excess weight is associated with an increased risk of catching, being hospitalised and dying from the virus, with the risks increasing progressively with higher levels of excess weight (PHE 2020).

So much for the health effects, what of the economic costs? In the USA, healthcare expenditures have risen from $6.9 \%$ of gross domestic product (GDP) in 1970 to $17.9 \%$ in 2017, driven by diet-related chronic health conditions. Mande et al (2020) estimate healthcare and indirect economic costs for cardiovascular diseases to be $\$ 316$ billion per year; for diabetes, $\$ 327$ billion per year; and for all obesity-related conditions, to be $\$ 1.72$ trillion per year. Globally, the externalities of US food system are estimated to total $\$ 12$ trillion, an amount greater than the entire food sector's revenue (Mande et al 2020).

In Europe, diabetes is the largest contributor to overall healthcare costs (Stedman et al 2020) and accounts for around 12\% of healthcare expenditures globally (Global Alliance for the Future of Food and IPES-Food 2017). In England, bed-day analysis showed 17\% of beds were occupied by patients with type 2 diabetes in 2017-18 and a total of $£ 5.5$ bn was spent on diabetes care (Stedman et al 2020). In 2014-15, the NHS spent $£ 6.1 \mathrm{~m}$ on obesity-related illhealth. The overall costs to society of obesity were estimated at $£ 27 \mathrm{bn}$ each year and rising to $£ 50$ bn by 2050 on current trends (PHE 2017).

For decades, poor diet has been treated as the fault of the individual with countless interventions to encourage us to eat a healthy diet. Yet, as the above figures show, results have not been impressive. Knowledge and awareness of nutrition is far greater than for our ancestors. How have we reached the state where we are eating ourselves to death? The answer lies in the food system for, as Bee Wilson points out (2019, p.6), "it makes no sense to presume that there has been a sudden collapse in willpower across all ages and ethnic groups since the 1960s".

\section{Nutrition and the food system}

Food systems are comprised of a series of stages, starting with agriculture and moving through processing, transporting, wholesaling and retailing (and packaging) to consumption itself (an activity that goes far beyond mere purchase). Each of these has been subject to considerable if uneven academic scrutiny, often in isolation from one another. Academic 
research tends to be siloed into different segments of the system. At one end, agricultural studies have highlighted the effects of capitalism on the industrialisation of food production. At the other end of the food system, much emphasis has been placed upon the power of mega-retailers and the competitive pressure this places on suppliers. And then a further literature is oriented around food consumption and associated cultures. ${ }^{4}$ But rather than these segments operating separately, it is their intersections that ultimately impact on food consumption. Corresponding structures and processes are unpacked in more detail below, as we show the thread leading from financial markets and/or neoliberal policies to the stomach.

\subsection{Financialized neoliberal food production}

Agricultural food production has been transformed by neoliberalism in general and financialization in particular. As with many other fields and topics, the financialization of food has benefitted from a recent and rapidly expanding literature, covering covered all aspects of the food chain, from land to retail (Isakson, 2014; Clapp, 2014; Williams, 2014 and Sommerville \& Magnan, 2015), although explicit attention to consumption has remained limited despite its being the endpoint of food chains. As Rossman and Greenfield (2006, p.2) put it, cited in Fine (2007): ${ }^{5}$

Of course, companies have always sought to maximize profit. What is new is the drive for profit through the elimination of productive capacity and employment. Transnational food processors, for example, now invest a significantly lower proportion of their profits in expanding productive capacity. Financial markets today directly reward companies for reducing payroll through closures, restructuring and outsourcing. This reflects the way in which financialization has driven the management of non-financial companies to "act more like financial market players".

One aspect of this is the financialization involved in speculative land grabbing which has already benefitted from its own healthy literature, Fairbairn (2015), Dixon (2014) and McMichael (2012) for example. ${ }^{6}$ But it has already departed from a stereotyped understanding based on foreign financiers acquiring land for purely speculative purposes. Indeed, finance and land grabbing need to be located more broadly across a number of dimensions. As Fairbairn (2015, p. 589) puts it: ${ }^{7}$

The clear-cut distinction between foreign and domestic was always illusory ... The capriciousness of global capital makes the foreigner a moving target, difficult to pin down for more than a moment. Today, the foreigner provides an object for popular outrage and for government policy action, but it is an unstable signifier with limited explanatory power.

In other words, the ownership of land has to be located in relation to existing as well new entrants, whether financial and/or foreign. And, for Sippel, Larder and Lawrence (2016), this is a matter of different and differentiated actors. For (p.12):

While some farmers appreciated the increased interest of financial actors in farmland as underpinning the value of their estates, others viewed this as a threat to family farming and an exacerbation of already unequally distributed access to land resources. 
Moreover, some farm family entrepreneurs have become financially attuned actors themselves and see the opportunities investment funds provide them as a means to increase their farm profitably and flexibility.

Thus, whilst some of the literature in populist vein, sees financialization as the latest factor undermining small-scale or native farmers, ${ }^{8}$ Sippel et al appropriately conclude that: 'It is especially important to avoiding constructing farmers as a singular and undifferentiated group of "victims" of a financialized food system' (p.2)..$^{9}$

This dovetails with a different source of differentiation arising out of the financialization of land, one that is keenly observed in the broader literature, which queries the extent to which financialization expands production or not (or constrains investment as for Rossman and Greenfield is typical of financialization)? On the one hand, land grabbing is seen as speculative acquisition of land that is otherwise left idle. On the other, it is associated with clearances of Amazonian forests for production of soya and other crops. Significantly, the farming literature offers a corrective to the notion that all financialization, especially as speculation par excellence, is at the expense of production. As Fairbairn (2014, p. 786) observes, referring to hybrids, "it is possible to use the land productively while simultaneously speculating on financial returns from its appreciation", for Isakson $(2014, \mathrm{p}$. 769), "the financialization of farmland has blurred the line between land as a productive asset and land as an object of speculation". She refers to the "blurring" of the role of finance along food chains, as does Brooks (2016, p. 75) of "financial and 'real' assets and activities'. Visser, Clapp and Isakson $(2015$, p. 544) point out that, "the private financial sector is conflicted about the types of risk that it is willing to assume. In particular, it is generally cautious to invest in actual agricultural production yet eager to speculate in related derivatives markets". Sommerville and Magnan $(2015$, p. 135) treat "farmland as both a productive and a financial asset”.

This raises a number of issues. What are the circumstances in which the acquisition of land by financiers leads to an expansion of production and productivity? As Li (2015, p. 567) suggests, this is a matter of "the dynamics of change in social relations" (italics in the original), and such "relations of access and exclusion are always going to be social and political to the core". ${ }^{10}$ In other words, the conditions under and through which finance gains access to land is crucial, as is acknowledged by Marx's theory of agricultural rent, with the potential for financialized land accelerating rather than obstructing accumulation (Fine, 2019).

This concerns how profits can best be made and, as observed in the literature, it is not simply a matter of economies of scale in farmland production but of economies of scope along value chains. Through conglomerates, financialized concentration is occurring along as well as within the separate elements of the chains of production, whether it be retailers, wholesalers, or providers of raw materials (Isakson, 2014). Thus, whilst large-scale retailers have financialized their own assets (Baud \& Durand, 2012), they have tended to continue to rely on subcontracting for other elements in the food chain. As Brooks (2016, p. 774) comments:

While financial actors have gained a sizeable stake in food sales ... food retailers earn more revenues from financial activities, either by redirecting cash flows into financial (rather than productive) investments or by diversifying their own activities into financial services such as credit cards, insurance products, etc. 
By contrast, Salerno (2014, p. 1710) recounts how "Cargill is a producer and trader of seed, feed, fertiliser, and agrochemicals. It is a landowner, cattle rancher, maker of transportation vehicles, biofuel producer and a provider of financial services".

Further, food has become increasingly attached to speculative commodity markets, for particular foods and through the rapid expansion of corresponding index funds. ${ }^{11}$ Expansion of these has been extraordinarily rapid but also shifting in nature, as particularly brought out by Lehecka (2014) with different regimes demarcated before and after 2004, and before and after the global financial crisis (GFC). What his empirical analysis shows is that (food) commodity markets can to a greater or lesser extent both track general movements in financial markets (more co-movement more recently) but also they may not track one another, suggesting commodity markets can serve as a safe haven when other markets turn down. Equally if not more important, however, is the observation of Isakson (2014, p. 759) that, in contrast to commodities such as oil, "in most areas of the global South, the spikes in global commodity prices have translated into stubbornly high food prices". ${ }^{12}$ This may be due to the way in which higher food prices can become consolidated in the form of higher land prices as capitalized rent, itself fueling financialization. And, of course, the speculative movement of food prices may or may not be common with one another, especially in light of capacity of some products to substitute for petroleum. Thus, under neoliberalism and accentuated by financialization, driven by the profit imperative, food systems are subject to increasing expansion of supply and cost reduction, for given quality (itself subject to branded invention). But, with the exception of the occasional, deliberate destruction of yield to sustain prices or heavy recession and stockpiling, food that is produced needs to be consumed.

\subsection{Creating an outlet for what is produced}

Commodified food systems are driven by the compulsion to sell and, thereby, providers have an incentive, if not need, to create a social compulsion to eat going far beyond physiological need. It is not so much whether this is so or not but how it is realized socially and systemically. Through what processes are food relations structured so that consumers systematically eat more and more?

First, as shown in a study of food systems as long ago as the mid-1990s, if fat, sugar and salt are produced (in dairy, sugar and meat systems for example), then they are going to be consumed (Fine et al, 1996). It is simply a matter of by whom and how, especially in processed foods, for example, where ingredients become cheaper, disguised and serve palatability and convenience. For instance, the rise in the UK of supermarket retailing had ensured the availability of a wider range of healthier low-fat milks, once the uniquely protected doorstep delivery was effectively abandoned. But with the agricultural system supporting production of high fat milk, the cream had to go somewhere. And so it did, into fancy cheeses and desserts, and manufactured foods, all equally readily available in the multiproduct supermarkets. Indeed, those at the forefront in the purchase of healthy milk were found to be equally prominent in the consumption of high cream products as well! A similar story can be told for sugar, with reduction in direct consumption from the sugar bowl or in home-baking (until Bake Off!) being compensated for by its incorporation within manufactured foods (alongside salt and unhealthy fats), sustaining its level of consumption per capita. Thus, analysis of the dairy and sugar systems indicated that healthy eating programmes for the consumer would tend at most to redistribute their consumption, and most likely towards those on low incomes, poor diets in the first place, and least able or willing to 
respond to health messages. ${ }^{13}$ This provided one major insight into food systems, as the socalled diseases of affluence associated with bad diets came to be recognised, namely the inconsistency between agricultural policy (produce more as cheaply as possible) and health policy (eat less and a balanced diet) with agricultural production (and food processing) prevailing over health.

Second, rising food production is associated with increasing availabilities of food. It is not only the different ranges of foods available, throughout the year without regard to seasons, but the appropriately dubbed convenience with which they are made available - through preservation as dried foods or in cans, by storage in fridge/freezers, ready meals, snacks, and ever more outlets for the provisioning of foods, by small and large stores (one for convenience, the other for bulk purchase), with the Deliveroo/Uber phenomenon being the most recent manifestation of the capacity to eat whatever you like whenever you like, all on top of takeaways, cafés, street foods, quite apart from home cooking in increasingly wellequipped kitchens with ever more ingredients and recipes to deploy. Third, perversely, the food industry is also appealing to us to be healthy, not necessarily by consuming less but via the expanding range of diet foods on the market.

\subsection{Material cultures of food consumption}

Food ranges over a huge range of cultural practices and beliefs, including the rise and fall of fashions alongside secular changes (in eating out for example, convenience foods, takeaways and deliveries, the displacement of work canteens, the rise of the snack and the sandwich, the coffee shop, fair trading, the organic, the celebrity chefs and diet gurus, as well as food scandals including mad cow disease and horsemeat, and so on). Whilst eating disorders are far from new, they have been intensified on an unprecedented scale under contemporary capitalism. Globalised, neoliberal financialized food systems are creating pressures to increase food consumption. However, given the confines of appetite and bodily functions (and corresponding health), the compulsion to eat has become complemented by an equally pervasive compulsion not to eat, but to diet or, at least, to eat healthily. The issue is how we receive, experience and respond to the dual compulsions to eat and to diet, and the circumstances in which we do so, and through the consumption of which foods and how.

In short, the food and diet industries are not only in some sense in conflict with one another but are also symbiotic and mutually supportive. This is an essential starting point for understanding social norms of food consumption. How the tensions between the two compulsions are resolved is vital in understanding the position of individual foods in our diets even if, as is apparent from obesity statistics (construction of which is itself evidence for tension to diet!), the compulsion to eat is of greater quantitative significance.

Food norms are highly complex and product-specific in the way that consumption relates to the underlying compulsions to eat and to diet. This is apparent in case of foods like sugar and dairy but applies in different ways, for example, for hot drinks. Are they taken to avoid calories, with or without sugar and/or biscuit, a smoke, for sociability, to ease boredom? The material culture for food comprises three elements - how food is materially provisioned, how it is attached to practices and cultures, and the relationship between the two. Food systems push for the expansion of profitable production against what are bodily capacities, leading to excessive consumption and an epidemic of obesity to accommodate profitable supply. As a result, the availability of food has become pervasive, in terms of what can be eaten, how and when. 
But it is not just the ubiquity of food that is characteristic of modern food systems but its corresponding capacity to serve as a focus to gratify our emotions. Traditional overconsumption at more and longer festivals now has its counterpart in the regular patterns of daily life, not only through provision of (cheap) food, anytime and anywhere, but as the way to indulge our emotional well-being. Food has become a key element in the material and cultural processes for gratification of the emotions, even more than for gratification of the stomach. In this sense, food has become both pliable and extensive in the cultures it can serve, as both cause and effect of its ubiquity.

Different food types are associated with different meanings which vary across cultures. These cultures may be rooted in tradition (such as Christmas turkey) but they are also shaped by agencies in food systems. Foods do not arrive with given meanings as such, although how they are provisioned conditions what meanings they can have. The construction of the meaning of foods necessarily complements, in part forms, the cultures and identities to which the consumer is attached. The food (including the diet industry) plays a role in this, for example, through advertising, packaging and branding.

But resulting cultures are often chaotic with the consumer required to interpret contradictory influences. For example, the message of 'treat yourself' sits alongside corresponding, and equally obsessive attention to body images with spin-offs ranging from the exercise industry to fat-removing surgeries. Similarly, the search for ethical consumption is riddled with incoherencies around equity, fairness, human (and animal) rights and so on. Cultural influences, then, are typically generated at a distance from consumers, and trickle down accordingly as opposed to only being actively initiated and made by individuals. Ways of constructing meaning take many forms and involve many parties, from advertising, to trademarking standards to branding. Numerous agents attempt to influence outcomes, from those who promote profit, to the regulators who promote healthy eating. Rather than increasing choice and opportunity, these pressures intensify the stresses around food. And those stresses are confronted in ways that are deeply conditioned by closed access to influence, with the budgets and reach of the food industries far exceeding those of governments whether in advice or policy not least in ideologically dubbing corresponding interventions as those of the nanny state at the expense of our freedom and enjoyment.

\section{Conclusion - ways forward}

People's diets are shaped by many factors including levels of deprivation (PHE 2017) and ethnicity (NHS 2019). Our contribution highlights how consumption outcomes are affected by the functioning across the overall system of food provisioning. When it comes to policy, most campaigns for promoting healthier consumption have sought to close the gap between ideal and actual diets through promoting one at the expense of the other. But given the range of factors that shape food consumption, it does not make sense to understand the determinants of diet by more or less deviation from what is projected to be ideal or healthy.

Everyone has some notion of whether they are eating healthily or not, and most also know whether they are going to try and do something about it. A targeted healthy diet might be good for the individual consumer (if observed) but not, in general for understanding the social epidemiology of obesity. What we eat is not determined by the greater or lesser success in targeting an ideal diet, so there is relatively little analytical purchase in trying to understand what we eat by deviation from what we ought to. 
By contrast to this ideal-type understanding of diet, dietary knowledge derives from a multiplicity of sources, and corresponding practices and experiences. While, food knowledge is one thing, eating patterns in practice reflect the range of material cultures of food systems outlined above. Healthy eating campaigns that target a healthy diet have failed miserably, in part for systemic reasons outlined above. What gets produced must more or less get consumed, and can be more a matter of expanding and redistributing the burden of fat, sugar and salt consumption, underpinning the diseases of affluence as marked by the contemporary global epidemic of obesity. Reducing food beliefs to information systems is at the very least terminologically inadequate. Food information systems (reduced to dietary advice or not) are a poor proxy for the much more widely cast notion of the material cultures of food, in which information as such is not even central.

In short, food systems underpin consumer cultures through which pressures both to consume and to abstain need to be (re)negotiated. Thus, our associations with foods are in main part shaped by the systems by which they are provided, and the reality of food consumption is recognizably a different world of food cultures than one of deviations from an ideal and satisfying diet.

A leading food issue has been recognised by the Labour Party in a welcome call for Boris Johnson to stop dithering on addressing child obesity, https://labour.org.uk/press/labourdemands-boris-johnson-stops-dithering-and-take-decisive-action-to-tackle-childhood-obesityjonathan-ashworth/ It proposes:

- Protect children from junk food marketing with restrictions on advertising;

- Create healthier retail environments, promoting healthy food choices in shops and supermarkets;

- Mandatory and clear calorie and nutritional labelling on all food and drinks;

- Ban the sale of energy drinks to children;

- Reverse the cuts to public health funding to roll out weight management programmes to support people to live healthier lives.

But this list only begins to scrape the surface in reaching down deep down into the systemic causes of our food crises, only marginally addressing food choices and their consequences. Consider, for example, what happened when the government did try to address cultures of food consumption due to estimates that "children aged under 16 were exposed to 15 billion junk food adverts online in 2019, versus 700 million two years earlier" (BBC, 2020). The government's proposal to "usher in some of the toughest digital marketing restrictions in the world by the end of 2022 " prompted a "letter ... signed by 800 food and drink manufacturers and 3,000 UK brands ... [complaining they had] not been given enough time to submit detailed objections ... [suggesting] advertisers could use sophisticated online tools to aim their advertisements at adult audiences, not children". This is indicative in just one small area not only of the power of food corporates, and the systems that underpin them, but also of a stubborn resistance to change - along the lines of "save the children and let them become obese in adulthood instead"! Shift, rather than address the problem.

All crises tend to shed a bright light on the nature of society in ways that are overlooked in what are taken to be normal times. The current pandemic is no exception and, in particular, through its incidence on those with dietary issues (as well as other aspects of morbidity derived from unemployment, low wages, poor housing, poverty, and so on), the pandemic of malnutrition has been exposed to those who care to see it but have ignored it during its global gestation over just a few generations. As brought out by Lang (2020), crises within and deriving from food will only be resolved by a doggedly determined transformation in the 
food system from land to mouth, going far beyond piecemeal calls to end dithering, see also Fine (2020).

And what is true of food also applies to finance, the environment and other excesses and deficiencies, rooted in and conducive to economic and social inequalities, as revealed and intensified by both the grand scale of the GFC, the pandemic and the crisis of dietary diseases and the everyday access to health, water, housing and so on. The tasks ahead demand huge shifts across the worlds of scholarship, popular discourse, policymaking and activism - from suspension of the abnormalities of neoliberalism in all its forms, and temporary and arbitrary "whatever it takes" to get by, to an entirely new normal. Struggles around food, like so many involving (private) consumption, do emerge spasmodically and in fragmented forms, from food banks to Marcus Rashford, but only where they are politicised beyond consumer politics to the systems of provision that underpin them are they liable to begin to lever progressive change on a meaningful scale, Bayliss and Fine (2020).

\section{REFERENCES}

Baines, J. (2017). Accumulating through food crisis?: Farmers, commodity traders and the distributional politics of financialization. Review of International Political Economy, 24(3), 497-537. DOI: 10.1080/09692290.2017.1304434

Baud, C. \& Durand, C. (2012). Financialization, globalization, and the making of profits by leading retailers. Socio-Economic Review, 10(2), 241-66

Bayliss, K. and B. Fine (2020). A guide to the systems of provision approach: Who gets what, how and why. Basingstoke: Palgrave.

Brooks, S. (2016). Inducing food insecurity: Financialisation and development in the post2015 Era. Third World Quarterly, 37(5), 768-80.

Clapp, J. (2014). Financialization, distance and global food politics. Journal of Peasant Studies, 41(5), 797-814.

Development Initiatives (2020). Global Nutrition Report 2020. Development Initiatives Poverty Research Ltd: Bristol.

Diabetes UK (2019). "Number of people with obesity almost doubles in 20 years", News Item from Diabetes UK, available from https://www.diabetes.org.uk/about us/news/numberobesity-doubles-twenty-years [accessed 1 February 2021]

Dixon, M. (2014). The land grab, finance capital, and food regime restructuring: The case of Egypt. Review of African Political Economy, 41(140), 232-48.

do Nascimento, R., Frederico, S. \& Saweljew, Y. (2019). Financial capital and land control: New rentiers on the Brazilian agricultural frontier. Revista, 22(50), 261-286.

Edelman, M., Oya, C., \& Saturnino, M. (2013). Global land grabs: Historical processes, theoretical and methodological implications and current trajectories. Third World Quarterly, 34(9), 1517-31.

Fairbairn, M. (2014). 'Like gold with yield': Evolving intersections between farmland and finance. Journal of Peasant Studies, 41(5), 777-95. 
Fairbairn, M. (2015). Foreignization, financialization and land grab regulation. Journal of Agrarian Change, 15(4), 581-91.

Fine, B. (2007). From sweetness to McDonald's: How do we manufacture (the meaning of) foods? The Review of Social \& Economic Studies, 29(2), 247-71.

Fine, B. (2019). Marx's rent theory revisited? Landed property, nature and value. Economy and Society, 48(3), 450-61.

Fine, B. (2020). Review of Feeding Britain: Our food problems and how to fix them. Journal of Agrarian Change, DOI: 10.1111/joac.12403, forthcoming.

Fine, B., Heasman M. \& Wright, J. (1998). What we eat and why: A socioeconomic approach to standard items in food consumption. In A. Murcott (Ed). The nation's diet: The social science of food choice, (pp. 95-111). London: Longmans.

Fine, B., Heasman, M. \& Wright, J. (1996). Consumption in the age of affluence: The world of food. London: Routledge.

GBD 2017 Diet Collaborators (2019). Health effects of dietary risks in 195 countries, 19902017: a systematic analysis for the Global Burden of Disease Study 2017. The Lancet, 393, 1958-1972. DOI: 10.1016/ S0140-6736(19)30041-8.

Ghosh, J. (2010). The unnatural coupling: Food and global finance. Journal of Agrarian Change, 10(1), 72-86.

Global Alliance for the Future of Food and IPES-Food (2017). "Unravelling the food-health nexus addressing practices, political economy, and power relations to build healthier food systems", available from https://futureoffood.org/wp-

content/uploads/2017/10/FoodHealthNexus_Full-Report_FINAL.pdf [accessed 1 February 2021]

Guthman, J. (2015). Binging and purging: Agrofood capitalism and the body as socioecological fix. Environment and Planning A, 47(12), 2522-36.

IDI (2017). Unjust enrichment: How the IFC profits from land grabbing in Africa, outsourcing development: Lifting the veil on the World Bank Group's lending through financial intermediaries. Retrieved from http://www.inclusivedevelopment.net/wpcontent/uploads/2017/04/Outsourcing-Development-Africa.pdf

IFA (2019). "Continuous mortality investigation". Briefing Note, Institute and Faculty of Actuaries, available from

https:/www.actuaries.org.uk/system/files/field/document/CMI\%20WP119\%20v01\%202019$03-07 \% 20-$

\%20CMI\%20Mortality\%20Projections\%20Mode1\%20CMI_2018\%20Briefing\%20Note.pdf [accessed 1 February 2021]

Isakson, S. (2014). Food and finance: The financial transformation of agro-food supply chains. Journal of Peasant Studies, 41(5), 749-75.

Lang, T. (2020). Feeding Britain: Our food problems and how to fix them, London: Pelican.

Lehecka, G. (2014). Have food and financial markets integrated? Applied Economics, 46(18), 2087-2095. 
Li, T. (2015). Transnational farmland investment: A risky business. Journal of Agrarian Change, 15(4), 560-68.

Mande, J., Willett, W., Auerbach, J., Bleich, S., Broad Leib, E., Economos, C., Griffin, T., Grumbly, T., Hu, F., Koh, H., Mozaffarian, D., Pérez-Escamilla, R., Seligman, H., Story, M., Wilde, P. \& Woteki, C. (2020). Report of the 50th Anniversary of the White House Conference on Food, Nutrition, and Health: Honoring the Past, Taking Actions for our Future. Boston, MA.

Mattioli, G., Roberts, C., Steinberger, J. \& Brown, A. (2020). The political economy of car dependence: A systems of provision approach. Energy Research \& Social Science, 66. DOI: 10.1016/j.erss.2020.101486.

McMichael, P. (2012). The land grab and corporate food regime restructuring. Journal of Peasant Studies, 39(3), 681-701.

Newman, S. (2009). Financialization and changes in the social relations along commodity chains: The case of coffee. Review of Radical Political Economics, 41(4), 539-59.

NHS (2019). “The NHS long term plan”, Report by National Health Service England, Available from https://www.longtermplan.nhs.uk/wp-content/uploads/2019/08/nhs-longterm-plan-version-1.2.pdf [accessed 1 February 2021]

NHS Digital (2020). "Statistics on obesity, physical activity and diet”, England, available from https://digital.nhs.uk/data-and-information/publications/statistical/statistics-on-obesityphysical-activity-and-diet/england-2020 [accessed 1 February 2021]

OECD (2017) "Obesity update 2017”, Organisation for Economic Cooperation and Development, available from: http://www.oecd.org/health/obesity-update.htm [accessed 1 February 2021]

PHE (2017). "Health matters: Obesity and the food environment", Guidance Notes, Public Health England, available from https://www.gov.uk/government/publications/health-mattersobesity-and-the-food-environment/health-matters-obesity-and-the-food-environment--2 [accessed 1 February 2021]

PHE (2020). "Excess weight and COVID-19 insights from new evidence”, Public Health England, available from https://assets.publishing.service.gov.uk/government/uploads/system/uploads/attachment_data /file/907966/PHE_insight_Excess_weight_and_COVID-19_FINAL.pdf [accessed 1 February 2021]

Rossman, P. \& Greenfield, G. (2006). Financialization: New routes to profit, new challenges for trade unions. Labour Education, Quarterly Review of the ILO Bureau for Workers' Activities, No 142. Retrieved from http://www.iufdocuments.org/www/documents/Financialization-e.pdf

Salerno, T. (2014). Capitalising on the financialisation of agriculture: Cargill's land investment techniques in the Philippines. Third World Quarterly, 35(9), 1709-727.

Sippel, S., Larder, N. \& Lawrence, G. (2016). Grounding the financialization of farmland: Perspectives on financial actors as new landowners in rural Australia. Agriculture and Human Values, online, DOI: 10.1007/s10460-016-9707-2. 
Sommerville, M. \& Magnan, A. (2015). 'Pinstripes on the prairies': Examining the financialization of farming systems in the Canadian prairie provinces. Journal of Peasant Studies, 42(1), 119-44.

Stedman, M, Lunt M, M. Davies, M. Livingston, C. Duff, A. Fryer, S. Anderson, R. Gadsby, M. Gibson, G. Rayman and A. Heald (2020) "Cost of hospital treatment of type 1 diabetes (T1DM) and type 2 diabetes (T2DM) compared to the nondiabetes population: a detailed economic evaluation", BMJ Open 2020;10:e033231. doi:10.1136/ bmjopen-2019-033231

Visser, O., Clapp, J. \& Isakson, S. (2015). Introduction to a symposium on global finance and the agri-food sector: Risk and regulation. Journal of Agrarian Change, 15(4), 541-48.

Williams, J. (2014). Feeding finance: A critical account of the shifting relationships between finance, food and farming. Economy and Society, 43(3), 401-31.

Wilson, B. (2019). The way we eat now: Strategies for eating in a world of change. Fourth Estate: London.

\footnotetext{
${ }^{1}$ This contribution draws heavily upon a few sections of Bayliss and Fine (2020).

${ }^{2}$ See https://www.foodnavigator.com/Article/2020/04/22/Coronavirus-and-obesity-Doctorstake-aim-at-food-industry-over-poor-diets

${ }^{3}$ For the evolving understanding of the incidence and (capacity for) treatment of diabetes, see the regular and increasing numbers of contributions to the Lancet and, especially and significantly, meta-studies.

${ }^{4}$ For an overview of the UK food system across all of its aspects, in the context of its chronic, and increasingly, acute conditions, see Lang (2020).
} 


\footnotetext{
${ }^{5}$ See also Newman (2009).

${ }^{6}$ On land grabbing more generally, see also collection introduced by Edelman et al (2013).

${ }^{7}$ See do Nascimento et al for the Brazilian case but also IDI (2017) for the indirect support offered to such land grabbing through financing from the World Bank.

${ }^{8}$ As Sommerville and Magnan (2015, p. 137) put it, "financialization accelerates the concentration of land and resources into fewer and larger farming units".

${ }^{9}$ This differentiation across and within the food systems in promoting and in response to financialization is explored in some detail in Baines (2017).

${ }^{10}$ With the role of the state crucial in this respect, as Visser et al $(2015$, p. 544) polemically observe, "states' objectives have shifted from ensuring that agriculture is supported by finance to ensuring that finance is supported by agriculture". Thus, subsidies to production can be capitalised in the value of land and securitised as a financial asset on condition of expanding, or constrained, production.

${ }^{11}$ Isakson (2014, p.758).

${ }^{12}$ See also Ghosh (2010). However, the trend in food prices, necessarily roughly estimated, has been downwards, by about a third in real terms, over the past fifty years prior to the spikes around the global financial crisis. Burgeoning rent and land prices come with productivity increases at rates higher than price decreases.

${ }^{13}$ See Fine et al (1996 and 1998) and Fine (1998) for these and other studies and their many implications. Guthman (2015, p.2522) quotes from a US comedy show: 'The government is really sending mixed messages here. First, they subsidize corn, making it so cheap we can gorge on subsidized corn syrup, and then they charge us more for health insurance just because our organs have caramelized ...Well, I'm sorry', he quipped, 'but our bodies are the only growth industry America has left'.
} 